\title{
Study on Blends of Polyurethane and Aniline-containing Poly(urethane-urea) Copolymer with Different Protonic Acid Dopants
}

\author{
Y. Z. Wang ${ }^{1, *}$, Y. C. Hsu ${ }^{1}$, L. C. $\mathrm{Chou}^{2}$ and K. H. Hsieh ${ }^{2}$ \\ ${ }^{1}$ Graduate School of Engineering Science and Technology (Doctoral program), National Yunlin University of \\ Science and Technology, Yunlin, 640 Taiwan \\ ${ }^{2}$ Department of Chemical Engineering, National Taiwan University, Taipei, 106 Taiwan \\ (*Author for correspondence; Fax: 886-5-5312056; E-mail: Wangzen@yuntech.edu.tw)
}

Received 7 August 2003; accepted in revised form 25 November 2003

Key words: copolymer, electronic conductivity, polyaniline, polyblend, polyurethane

\begin{abstract}
Blends of polyurethane (PU) and aniline-containing poly(urethane-urea) (PUUA) copolymer doped with different protonic acids, including camphorsulfonic acid (CSA) and dodecylbenzenesulfonic acid (DBSA), were prepared and studied. According to those DMA and DSC results, the blends show a partial compatibility and purification effect between the composed components of the blends. The blends using CSA as a dopant resulted in better heat resistant and tensile strength but poorer electronic conductivity than that of DBSA doped one.
\end{abstract}

\section{Introduction}

The conductive polymer is promising and attractive since it may lead to materials with conductivity similar to metals, with flexibility and processability like plastics, and possibly with transparency too $[1,2]$. Although polymers, in general, have been known and employed in various fields as dielectric or insulation materials for a long time, their potential to function as conductive substances were experimentally confirmed as early as in 1970s [3, 4]. Among conducting polymers, polyanilines (PANI) have received great attention due to its ease of synthesis, adequate degree of conductivity including unique conduction mechanism, good stability in the presence of oxygen/water, and low production cost [5-17]. However, it had been known that polyaniline salts, emeraldine hydrochloride, is generally insoluble in common organic solvents [18]. It had been only soluble in concentrated sulfuric acid [19], until it was recently found that the functionalized protonic acids like CSA and DBSA together with phosphoric acid ester, etc., enabled polyaniline salts soluble in organic solvents such as $m$-cresol, chloroform, xylene and dimethylsulfoxide (DMSO), etc., as well as NMP [20-22]. Due to the difficulty in thermal processing and its limited solubility in common solvent, PANI had been considered as an intractable polymer. Therefore, the processibility of polyaniline has been the subject in past decades. The techniques to prepare copolymers in order to improve the processibily and mechanical property is one of the effective methods. It is found that poly(aniline-co-toluidine) copolymer [23, 24] and aniline-containing poly(ureathane-urea) copolymer [25] have better solubility than homopolymers in various organic solvents. Additionally, blending PANI with thermoplastic matrix in the molten state has been shown to be an effective way to improve processability and mechanical properties $[8,26-28]$. This is due to the doping of functionalized protonic acid (FPA) which were found to be able to dope PANI and, at the same time, increase the solubility of the resulting PANI complex in common organic solvents [29-31], allowing solution blending. The present work is studying rubber-like conductive blends containing polyurethane (PU) and aniline-containing poly(urethane-urea) copolymer in terms of degree of compatibility, thermal, mechanical and electrical conductivity. In order to ensure better compatibility with PU, PANI oligmer used as chain extender in the preparation of PU to form copolymers and doped with different FPAs including camphorsulfonic acid (CSA) and dodecylbenzenesulfonic acid (DBSA), and subsequently blended with each type of PU copolymers in solution.

\section{Experimental}

\section{Materials}

The materials used in the preparation and testing are listed in Table 1.

\section{Preparation of PU Prepolymer}

PU prepolymer was synthesized by solution polymerization of 4-4' dipheny 1 methane diisocyanate (MDI) with polyether type polyol (polytetramethylene oxide with a molecular weight of 1000, PTMO1000) with 2:1 molar ratio of MDI to PTMO1000 in a NMP solution. The reaction between 
Table 1. List of materials

\begin{tabular}{lll}
\hline Material & Composition & Source \\
\hline Aniline & $\mathrm{C}_{6} \mathrm{H}_{5} \mathrm{NH}_{2}$ & TCI \\
Ammonia persulfate (APS) & $\left(\mathrm{NH}_{4}\right)_{2} \mathrm{~S}_{2} \mathrm{O}_{8}$ & Showa \\
Hydrochloric acid & $\mathrm{HCl}$ & Matsunoen \\
Ammonium water & $\mathrm{NH}_{4} \mathrm{OH}$ & Showa \\
$p$-phenylene diamine ( $p$-PDA) & $\mathrm{NH}_{2} \mathrm{C}_{6} \mathrm{H}_{5} \mathrm{NH}_{2}$ & ACROS \\
Polytetramethylene oxide (PTMO) & $\mathrm{HO}_{-}\left[\left(\mathrm{CH}_{2}\right)_{4}-\mathrm{O}-\right]_{n} \mathrm{H}$ & Aldrich \\
4,4'-diphenylmethane diisocyanate (MDI) & $\mathrm{OCNC}_{6} \mathrm{H}_{4} \mathrm{CH}_{2} \mathrm{C}_{6} \mathrm{H}_{4} \mathrm{NCO}$ & Aldrich \\
1-methyl-2-Pyrrolindone (NMP) & $\mathrm{CH}_{3} \mathrm{NCH}_{2} \mathrm{CH}_{2} \mathrm{CO}_{2}$ & Fisher \\
1,4-butanediol (1,4-BD) & $\mathrm{HOCH}_{2} \mathrm{CH}_{2} \mathrm{CH}_{2} \mathrm{CH}_{2} \mathrm{OH}$ & TEDIA \\
Dimethylformamide (DMF) & $\left(\mathrm{CH}_{3}\right)_{2} \mathrm{NCHO}^{-}$ & TEDIA \\
\hline
\end{tabular}

MDI and PTMO1000 was kept for $4 \mathrm{~h}$ under dry nitrogen atmosphere at $70^{\circ} \mathrm{C}$. The details of the PU prepolymer synthesis can be found elsewhere [32, 33].

\section{Preparation of Amine-Terminated Polyaniline Oligomer Powders (OPA) [25, 34-38]}

Aniline and ammonia persulfate, mixed with $1 \mathrm{M} \mathrm{HCl}$ aqueous solution, were individually kept in a refrigerator overnight. To control the molecular weight, a suitable $p$-phenylene diamine was mixed with the aniline solution before APS aqueous solution was added dropwise into the aniline solution and the mixture was kept at $0 \sim 5^{\circ} \mathrm{C}$ for $24 \mathrm{~h}$ with continuous stirring. The resulting polyaniline was isolated by filtration and dedoped by stirring in $0.1 \mathrm{M}$ aqueous solution of ammonia for $12 \mathrm{~h}$ followed by filtration. The cake was dried in a vacuum oven for 3 days and ground into powder by mortar. The molecular weight and molecular weight distribution of the resulting OPA, were measured by gel permeation chromatogaphy.

\section{Preparation of $P U$ and Aniline-Containing \\ Poly(urethane-urea) Copolymers (PUUA) [25]}

A two-step condensation reaction was used to prepare the PU and PUUA. The first step was preparation of the prepolymer as mentioned in the previous section. The second step is chain extension of the prepolymer. The prepolymer was diluted in NMP. Two chain extenders, OPA and 1,4 butanediol $(1,4 \mathrm{BD})$ mixtures in the NMP solution with the desired ratio, were added into the diluted prepolymer solution with an equal equivalent amount at $70^{\circ} \mathrm{C}$ until the $-\mathrm{NCO}$ group disappeared, followed by drying in a vacuum oven for 3 days. The molar ratio of the OPA relative to the $1,4 \mathrm{BD}$ was varied to control the content of the aniline-containing urethane-urea blocks in the copolymers but keeping the total equivalent amount equal to that of PU-prepolymers. In the study, the OPA content in the copolymer was adjusted to $30 \mathrm{wt} \%$ (samples were labeled PUUA30). The addition of protonic acid dopant (CSA or DBSA) to NMP solution was carried out to dope copolymers.

\section{Preparation of PU/PUUA30 Blends}

The blends of PU/PUUA30 were prepared in solution. NMP solutions of PU prepolymer and 1,4 BD were mixed with the doped copolymer solution to form blends at $70^{\circ} \mathrm{C}$. The solution mixture was stirred for overnight and followed by casting in a petri dish and dried in hood and further dried at $90{ }^{\circ} \mathrm{C}$ under vacuum for 3 days to remove the residual solvent. The blends containing 25, 50 and $75 \mathrm{wt} \%$ of PUUA30 were prepared.

\section{Characterization}

\section{Infrared Spectroscopy}

Fourier-transform infrared spectroscopic (FTIR) measurements of the synthesized materials were carried out on a Bio-Rad FT-40 spectrophotometer. Sixty-four scans were signal-averaged at a resolution of $2 \mathrm{~cm}^{-1}$ from $4000 \mathrm{~cm}^{-1}$ to $400 \mathrm{~cm}^{-1}$. Samples were prepared by cryogenically grinding the synthesized polymer with $\mathrm{KBr}$ (polymer: $\mathrm{KBr}=1$ : 20) and compressing the mixture to a disk.

\section{Thermogravimetric Analysis}

Thermogravimetric analysis (TGA) thermograms were obtained by using a Perkin-Elmer TGA-7 in a dry nitrogen atmosphere at $20^{\circ} \mathrm{C} / \mathrm{min}$.

\section{Differential Scanning Calorimetry}

Differential scanning calorimetric (DSC) measurements of the synthesized materials were performed on a Dupont 2010 from $-100^{\circ} \mathrm{C}$ to $200^{\circ} \mathrm{C}$ in a dry nitrogen atmosphere with a heating rate of $10^{\circ} \mathrm{C} / \mathrm{min}$.

\section{Dynamic Mechanical Analysis}

Dynamic mechanical analysis (DMA) of samples was achieved by using a Dupont 983 DMA unit at a frequency of $1 \mathrm{~Hz}$ at $5^{\circ} \mathrm{C} / \mathrm{min}$ from $-100^{\circ} \mathrm{C}$ to $200^{\circ} \mathrm{C}$. The sample dimension is $50 \mathrm{~mm} \times 5 \mathrm{~mm} \times 0.15 \mathrm{~mm}$ and the test mode is extension.

\section{Tensile Strength}

The tensile strength of the sample was determined by a Tensilon tester (Model: TCF-FC, Yashima Works). The test procedures followed ASTM-D412 with a crosshead speed of $50 \mathrm{~mm} / \mathrm{min}$. 


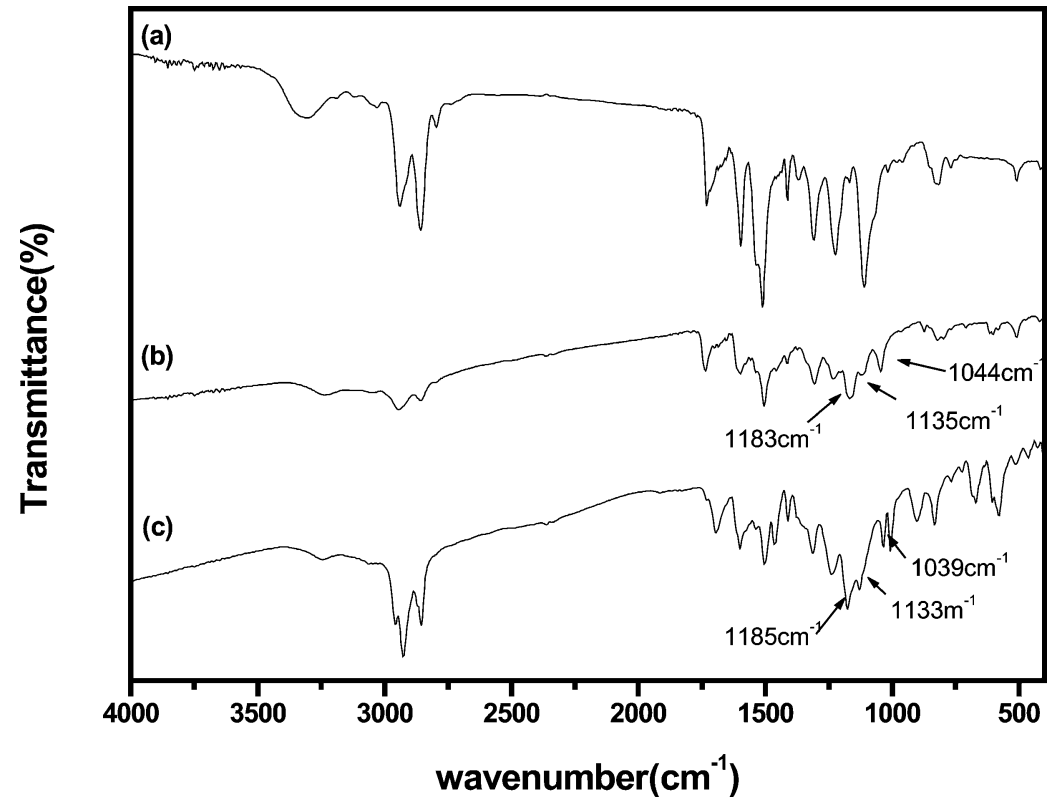

Figure 1. FTIR spectra of the PUUA30 copolymer: (a) before doping; (b) after doping by CSA; (c) after doping by DBSA.

Table 2. Average molecular weight and polydispersity of the polymers

\begin{tabular}{lccl}
\hline Polymer & $M_{\mathrm{w}}{ }^{\mathrm{a}}\left(\mathrm{g} \mathrm{mol}^{-1}\right)$ & $M_{\mathrm{n}}{ }^{\mathrm{a}}\left(\mathrm{g} \mathrm{mol}^{-1}\right)$ & $M_{\mathrm{w}} / M_{\mathrm{n}}$ \\
\hline OPA & 2,327 & 1,380 & 1.686 \\
PU & 113,400 & 37,300 & 3.04
\end{tabular}

${ }^{\text {a}}$ Determined by GPC in DMF.

\section{Surface Resistance}

The surface resistivity of the synthesized materials was measured by using a Harles Water Item 19670 surface resistivity meter.

\section{Measurements of Average Molecular Weight and Molecular Weight Distribution}

The average molecular weight and molecular weight distribution of the synthesized polymers, was determined by gel permeation chromatography (GPC, Testhigh model 500) using low polydispersity polystyrene as a standard at $40^{\circ} \mathrm{C}$. DMF was used as an eluent. The number average molecular weight $\left(M_{\mathrm{n}}\right)$, weight average molecular weight $\left(M_{\mathrm{w}}\right)$ and molecular weight distribution $\left(M_{\mathrm{w}} / M_{\mathrm{n}}\right)$ as polydispersity index of OPA and PU are determined by GPC in DMF and list in Table 2. The $M_{\mathrm{w}}, M_{\mathrm{n}}$ and $M_{\mathrm{w}} / M_{\mathrm{n}}$ of OPA are 2327 , 1380 and 1.686 , respectively. The $M_{\mathrm{w}}, M_{\mathrm{n}}$ and $M_{\mathrm{w}} / M_{\mathrm{n}}$ of PU are 113,400, 37,300 and 3.04, respectively. However, $M_{\mathrm{w}}, M_{\mathrm{n}}$ and $M_{\mathrm{w}} / M_{\mathrm{n}}$ data of the resulted copolymer (PUUA) can not be shown due to its low solubility in DMF solution.

\section{Results and Discussion}

In order to characterize the doping effect on PUUA copolymers by the protonic acid, FTIR spectra of the undoped and doped PUUA copolymers are compared, as shown in Figure 1. The characteristic absorptions of interest are
$\mathrm{N}=$ quinoid $(\mathrm{Q})=\mathrm{N}\left(1165 \mathrm{~cm}^{-1}\right), \mathrm{Q}=\mathrm{N}^{+} \mathrm{H}$-benzoid $(\mathrm{B})$ or $\mathrm{B}^{-} \mathrm{NH}-\mathrm{B}\left(1135 \mathrm{~cm}^{-1}\right), \quad-\mathrm{C}=\mathrm{O}\left(1750 \mathrm{~cm}^{-1}\right), \quad \mathrm{R}-\mathrm{SO}_{3}^{-}$ $\left(1043 \mathrm{~cm}^{-1}\right)$ for CSA or DBSA doping polyaniline, respectively. The disappearance of the main chain $\mathrm{N}=\mathrm{Q}=\mathrm{N}$ absorption and the appearance of characteristic absorptions at around $1135 \mathrm{~cm}^{-1}$ and $1043 \mathrm{~cm}^{-1}$ after doping indicate doping has taken place. Furthermore, it has been reported that the color of the copolymer (due to the formation of polaron) will change from deep blue to deep green after effective doping [39]. This phenomenon was also observed in our copolymers.

\section{Thermal Analysis}

Figures 2 and 3 show TGA thermograms of the blends containing polyurethane PU and PUUA copolymers doped with CSA and DBSA (PUUA30(CSA)) and (PUUA30(DBSA)), respectively. The common feature in both TGA results is that the temperature of the initial degradation decreases with the copolymers content. The explanation for this behavior can be dual: volatilization of the dopants and depression of heat resistance from dilution. As the degree of initial degradation is not proportional to the contents of the copolymers, this factor apparently is not the dominant one. The decrease of the initial degradation temperature of the blend becomes much smaller or even negligible when the copolymer content reaches $50 \mathrm{wt} \%$, while the degree of the initial degradation ceases to increase when the copolymer content is beyond $75 \mathrm{wt} \%$ for PUUA30(CSA) blends. This is thought to result from phase inversion where the copolymer replaces $\mathrm{PU}$ to be the dominant phase. In addition, CSA possesses carbony1 groups $(\mathrm{C}=\mathrm{O})$ which facilitate hydrogen bonding (H-bonding) with NH groups of OPA and urethane linkages. This reduces the possibility of volatilization of CSA and also strengthens the blend structure. Therefore, the decrement of the initial degradation temperature is greater in the case of 


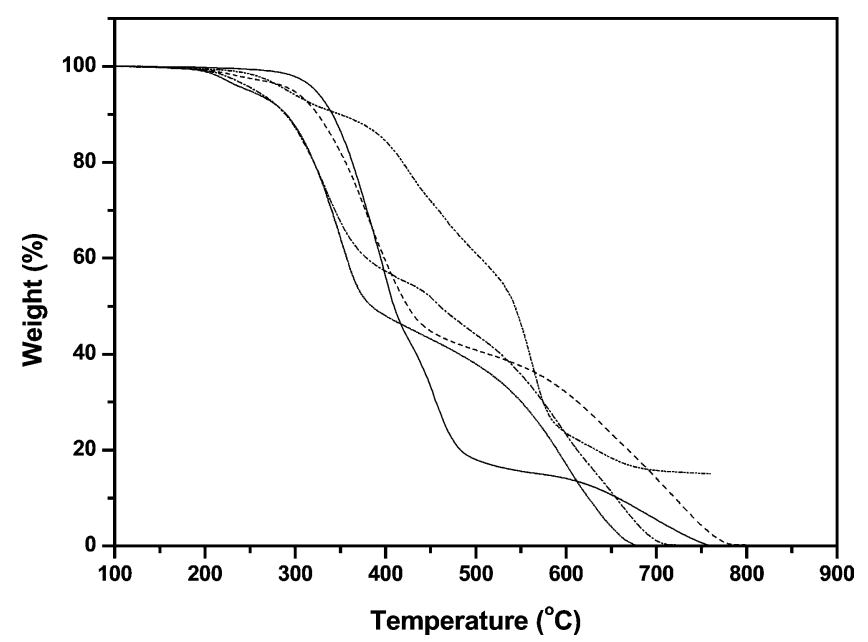

Figure 2. TGA thermograms of the PUUA30(CSA)/PU blends. PUUA30(CSA)/PU: —: 0/100; ---.: 25/75; . . .: 50/50; -...-: 72/25; .... $100 / 0$

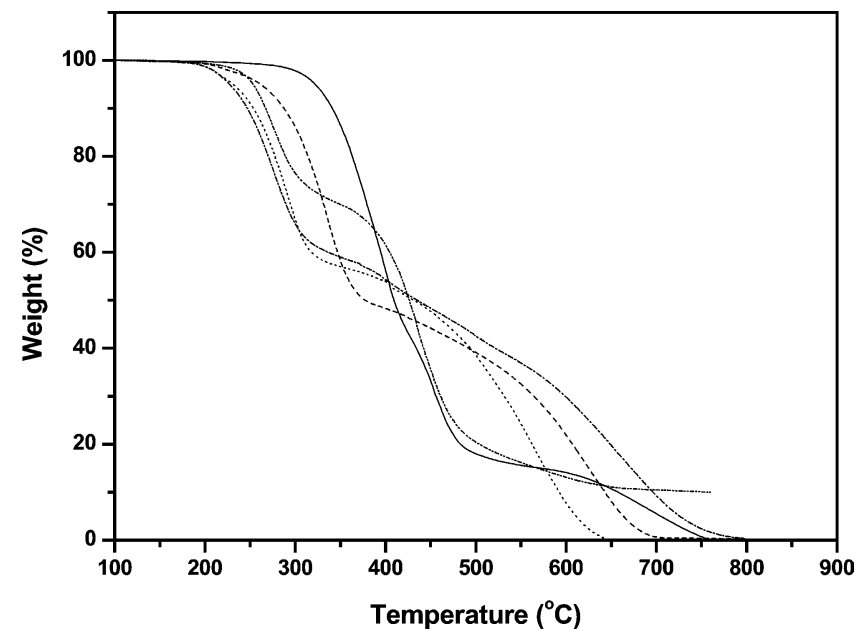

Figure 3. TGA thermograms of the PUUA30(DBSA)/PU blends. PUUA30(DBSA)/PU: —: 0/100; --: 25/75; . . .: 50/50; -..--: 75/25; -. --: $100 / 0$.

PUUA30(DBSA) blends than that of PUUA30(CSA) blend, as seen in Table 3 .

It seems CSA doped copolymer demonstrates higher degradation temperature than that of DBSA doped one due to either the intermolecular H-bonding or shorter dangling side dopants.

\section{Mechanical Property}

The loss modulus of the PUUA30(CSA) blend as a function of temperature determined by DMA are displayed in Figure 4. PU exhibits two relaxation peaks at $-32^{\circ} \mathrm{C}$ and $-82^{\circ} \mathrm{C}$ in its loss modulus curve respectively. The higher one is assigned as the glass transition temperature $\left(T_{\mathrm{g}}\right)$ of the soft-segment-rich regions as segmented PU is well known to show micro-phase separation [39] consisting of hardsegment-rich regions and soft-segment-rich regions, each showing its relaxation behavior whose characteristic temperature is higher than $100^{\circ} \mathrm{C}$ for the hard-segment regions. The lower one is a sub-glass transition resulting from rather localized chain relaxation ( $\beta$-transition) of the soft segments.

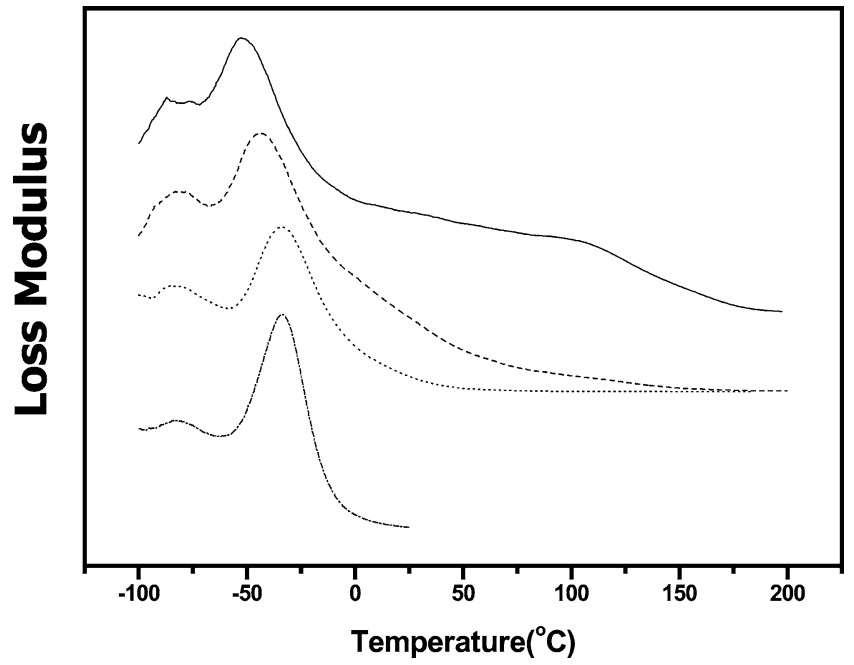

Figure 4. Loss modulus of the PUUA30(CSA)/PU blends. PUUA30(CSA)/PU: -...: 0/100, . . : 25/75; - - -: 50/50; —: 75/25.

With the addition of the copolymer, $T_{\mathrm{g}}$ 's of the blends decrease and the transition peaks become broad and less intensive. By contrast, the $\beta$-transition increases with the copolymer content. Generally, the shift trend of $T_{\mathrm{g}}$ can be considered as the index of miscibility of polyblends. The observed phenomenum in Figure 4 is thought to be due to the purification effect $[40,41]$, that is, the copolymers in the blends extract part of the hard segments out from the PU phase resulting in the decrease of the $T_{\mathrm{g}}$ 's of the soft-segment-rich regions of segmented PU. The extracting driving force is believed to be the H-bonding from the carbonyl groups of CSA doped copolymers since there is no decreasing $T_{\mathrm{g}}$ 's with copolymers for DBSA doped copolymers which owns no carbonyl groups in the dopants as shown in Figure 5. Note that the loss modulus data of the neat copolymer are not available due to the difficulty to form membrane for DMA testing and thus the DMA results are not conclusive in determining the blend miscibility. The changing trend of the $T_{\mathrm{g}}$ values obtained from DSC thermograms, indicates that $T_{\mathrm{g}}$ 's decrease with increasing copolymer content, as listed in Table 3. Combining the DMA and DSC results, blends of PUUA30(CSA) copolymer and PU are partially miscible. Although the improvement of miscibility between OPA and PU is made by chemically incorporating OPA into PU to form copolymers, the intrinsic immiscibility between PANI and thermoplastics [41], in the case, its blend component, PU, can not be fully eliminated.

The loss modulus curves of the PUUA30(DBSA) blends behave approximately the same way as the PUUA30(CSA) series, although the shift of $T_{\mathrm{g}}$ 's of the blends is less significant, as seen in Figure 5. The intensified $\beta$-transition with the addition of the PUUA30(DBSA) copolymer is noticed as observed in Figure 5. This may result from the increase in free volume, thus facilitating the short range chain movement, due to the partial blend miscibility. Furthermore, through the formation of $\mathrm{H}$-bonding between $\mathrm{NH}$ groups of OPA and $\mathrm{C}=\mathrm{O}$ groups of hard segments of $\mathrm{PU}$, hard segment of PU may be attracted towards OPA moiety 
Table 3. Degradation temperature and glass transition temperature of the PU/PUUA30 blends

\begin{tabular}{clllll}
\hline & \multicolumn{2}{c}{$T_{\mathrm{d}}(5 \mathrm{wt} \%$ degradation $)\left({ }^{\circ} \mathrm{C}\right)^{*}$} & & \multicolumn{2}{c}{$T_{\mathrm{g}}\left({ }^{\circ} \mathrm{C}\right)$} \\
\cline { 2 - 3 } \cline { 5 - 6 } $\begin{array}{l}\text { Copolymer } \\
(\text { wt } \%)\end{array}$ & $\begin{array}{l}\text { PUUA30 } \\
\text { (CSA)/PU }\end{array}$ & $\begin{array}{l}\text { PUUA30 } \\
(\text { DBSA }) / P U\end{array}$ & & $\begin{array}{l}\text { PUUA30 } \\
(\mathrm{CSA}) / \mathrm{PU}^{* *}\end{array}$ & $\begin{array}{l}\text { PUUA30 } \\
(\mathrm{CSA}) / \mathrm{PU}^{* * *}\end{array}$ \\
\hline 0 & 322 & 322 & & -46 & -32 \\
25 & 297 & 262 & & -55 & -34 \\
50 & 248 & 229 & & -56 & -44 \\
75 & 246 & 218 & & -64 & -52 \\
100 & 196 & 168 & & -64 & - \\
\hline
\end{tabular}

${ }^{*} T_{\mathrm{d}}$ measured by TGA.

${ }^{* *} T_{\mathrm{g}}$ measured by DSC.

**** $T_{\mathrm{g}}$ measured by DMA.

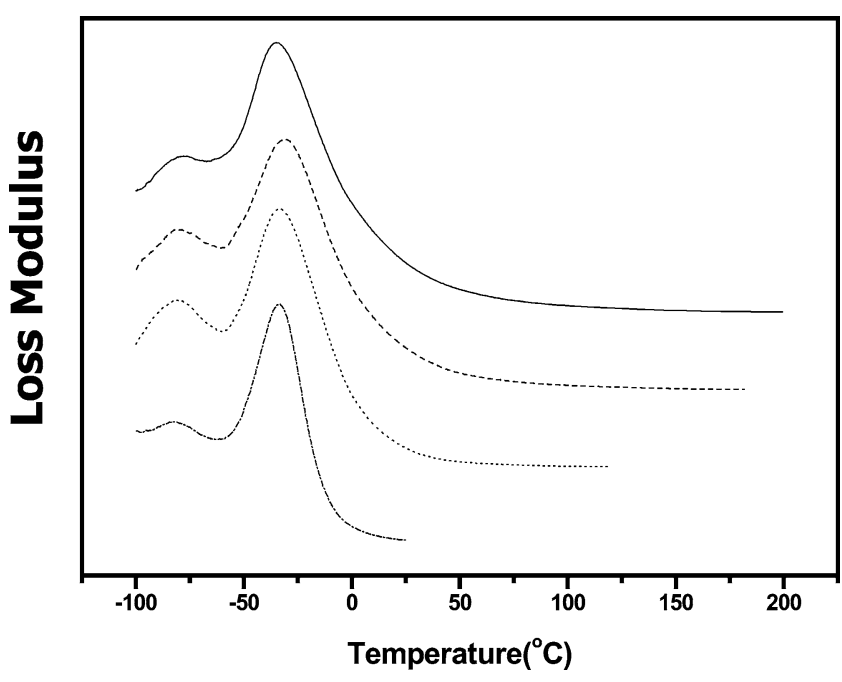

Figure 5. Loss modulus of the PUUA30(DBSA)/PU blends. PUUA30(DBSA)/PU: -.-.-: 0/100; ․ .: 25/75; ---: 50/50; —: 75/25.

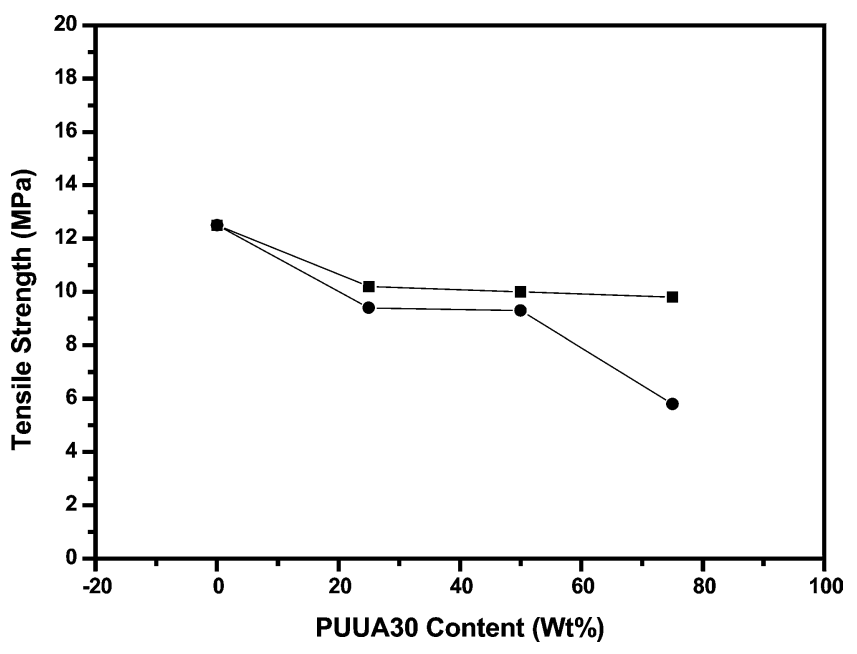

Figure 6. Tensile strength of the PUUA30/PU blends: - PUUA30(DBSA).

and reduce the extent of restraint on neighboring short-range chain relaxation.

Figure 6 displays the tensile strength of the PUUA30(CSA) and PUUA30(DBSA) blends. Tensile strength of both blend systems exhibits a decreasing trend with the addition of copolymer. This may result from the pu-

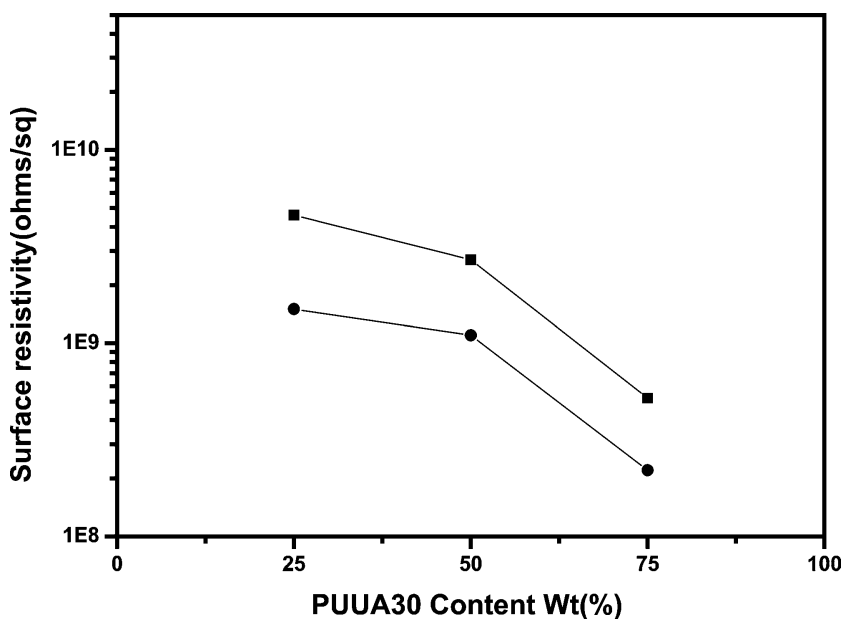

Figure 7. Surface resistivity of the PUUA30/PU blends: PUUA30(CSA); - PUUA30(DBSA).

rification effect and partial miscibility of the blends. Moreover, PANI is a brittle material and its presence in the blends can become a potential weak region under tension. This factor can be further verified from the low tensile strength shown by the blends with high copolymer contents where the mechanical characteristics of the copolymers (and thus PANI) are dominant. When the tensile strength of the two blends systems is compared, PUUA30(CSA) blends have greater strength than that of PUUA30(DBSA). This is possibly due to the additional molecular interaction between the CSA and PU. CSA can be employed not only to dope PANI but also form $\mathrm{H}$-bonding by its carbonyl groups with the $\mathrm{NH}$ groups either in PANI or PU. This bridging effect by CSA can lead to an enhanced mechanical performance.

\section{Conductivity}

Conductivity of the blends is evaluated by the measurements of their surface resistance and the results can be seen in Figure 7. PU's surface resistance is at the order of $10^{16} \Omega / \mathrm{sq}$ which is not shown in the graph. As expected, surface resistance of the blends decreases with increasing anilinecontaining copolymer concentration. Within the blends studied, the lowest surface resistance is about $5.2 \times 10^{8} \Omega / \mathrm{sq}$ for the PUUA30(CSA) blends and $2.2 \times 10^{8} \Omega /$ sq for the 
PUUA30(DBSA) blends, which is about the same range as anti-electrostatic material according to the Electronic Industry Association (EIA) standard $\left(10^{6} \sim 10^{9} \Omega / \mathrm{sq}\right)$. In addition, the PUUA30(DBSA) blends have smaller surface resistance than the PUUA30(CSA) at the same copolymer concentration. It has been proposed that conductivity of PANI-containing materials closely depends on the completeness of the conducting PANI network [33]. The H-bonding forming possibility of CSA may disperse the doped PANI too finely to form a fully connected network in the blends and, therefore, adversely affect the electrical behavior.

\section{Conclusions}

Blends of PU and PUUA copolymer doped with different protonic acids including CSA and DBSA, were prepared in a NMP solution and their degree of compatibility, thermal, mechanical and electrical properties were investigated. With the addition of copolymers, blends thermally degraded at lower temperatures due to dopant volatilization and depression of heat resistance of PU, with the latter being more influential. According to the DMA and DSC results, the blends are partially miscible. As a result of the partial miscibility of the blends and lower molecular weight of PU, tensile strength of the blends decreases with increasing copolymer concentration. Surface resistance of the blends decreases with increasing content of the conducting copolymer. Blends with $75 \mathrm{wt} \%$ copolymers have surface resistance at the order of $10^{8} \Omega / \mathrm{sq}$ and thus are capable of being used as anti-electrostatic materials. The H-bonding formed between $\mathrm{C}=\mathrm{O}$ groups of CSA and $\mathrm{NH}$ groups of PANI or PU changes the thermal properties and enhances mechanical strength but not the electrical property of the blends. Based on tensile strength and conductivity, the blends containing about $40 \sim 50 \mathrm{wt} \%$ of PUUA30 possess the suitable propertity.

\section{Acknowledgment}

The authors acknowledge with gratitude financial support from the National Science Council, Taiwan, R.O.C through grant No. 91-2622-E-224-005-CC3.

\section{References}

1. N. F. Colaneri and L. W. Shacklette, IEEE Trans. Instrum. Meas., 41, 291 (1992).

2. P. Juvin, M. Hasil, J. Fraysee, J. Planes, A. Pron and I. KulszewiczBajer, J. Appl. Polym. Sci., 74, 471 (1991).
3. T. Ito, H. Shirakawa and S. Ikeda, J. Polym. Sci., Polym. Chem. Ed., 12, 11 (1974).

4. C. K. Chiang, C. R. Fincher, Y. W. Park, A. J. Hegger, H. Shirakawa, E. J. Luis, S. C. Gau and A. G. MacDiarmid, Phys. Rev. Lett., 39, 1089 (1977).

5. S. H. Goh, H. S. O. Chan and C. H. Ong, J. Appl. Polym. Sci., 68, 1839 (1998)

6. R. Faez, W. A. Gazotti and M. De Paoli, Polymer, 40, 5497 (1999).

7. W. M. De Azevedo, J. M. De Soiza and J. V. De Melo, Synth. Met., 100, 241 (1999).

8. O. Y. Ikkala, J. Laakso, K. Vakiparta, H. Ruohonen, H. Jarvinen, T. Taka, P. Passiniemi and J. E. Osterholm, Synth. Met., 69, 97 (1995).

9. D. Macinnes and B. L. Funt, Synth. Met., 25, 235 (1988).

10. Y. Cao and P. Smith, Polymer, 34, 3139 (1993).

11. F. Lus, Polymer, 35, 2915 (1994).

12. M. Leclerc, J. Guay and L. H. Dao, Macromolecules, 22, 649 (1989).

13. M. Leclerc, J. Guay and L. H. Dao, J. Electroanal. Chem., 251, 21 (1988).

14. D. Kumar, Eur. Polym. J., 35, 1919 (1999).

15. D. Kumar and R. C. Sharma, Eur. Polym. J., 34, 1053 (1998).

16. D. Kumar, PhD Thesis, University of Delhi, 1998.

17. Z. H. Wang, A. Ray, A. G. MacDiarmid and A. J. Epstein, Phys. Rev., B43, 4373 (1991).

18. M. G. Han and S. S. Im, J. Appl. Polym. Sci., 67, 1863 (1998).

19. A. Andreatta, Y. Cao, J. C. Chiang, A. J. Heeger and P. Smith, Synth. Met., 26, 1383 (1988).

20. A. Pron, J. Laska, J. E. Osterholm and P. Smith, Polymer, 34, 4235 (1993).

21. A. G. MacDiarmid and A. J. Epstein, Synth. Met., 65, 103 (1994).

22. M. G. Han, Y. J. Lee, S. W. Byun and S. S. Im, Synth. Met., 124, 337 (2001).

23. Y. Wei, R. Hariharan and S. A. Patel, Macromolecules, 23, 758 (1990).

24. D. Kumar, Synth. Met., 114, 369 (2000).

25. Y. Z. Wang, Y. C. Hsu, R. R. Wu and H. M. Kao, Synth. Met., 132, 151 (2003).

26. M. Zilberman, A. Siegmann and M. Narkis, J. Macromol. Sci. Phys., B39, 333 (2000).

27. M. Zilberman, A. Siegmann and M. Narkis, J. Polym. Eng., 20, 97 (2000).

28. M. S. Pinho, M. M. Gorelova, M. Dezzoti, B. G. Soares and A. J. Pertsin, J. Appl. Polym. Sci., 70, 1543 (1998).

29. Y. Cao, P. Smith and A. J. Heeger, Appl. Phys. Lett., 60, 2711 (1992).

30. Y. Cao, P. Smith and A. J. Heeger, Synth. Met., 57, 3514 (1993).

31. A. J. Heeger, Synth. Met., 55-57, 3471 (1993).

32. D. C. Liao, K. H. Hsieh, Y. C. Chern and K. S. Ho, Synth. Met., 87, 61 (1997).

33. K. S. Ho, K. H. Hsieh, S. K. Huang and T. H. Hsieh, Synth. Met., 107, 65 (1999).

34. H. L. Frish, Bri. Polym. J., 17, 149 (1985).

35. Y. Wei, G.-W. Jang, Y. Sun and X. Tang, J. Polym. Sci., Part C, 28, 81 (1990).

36. Y. Wei, US Pat. No. 4, 940, 517 (1990).

37. Y. Wei, J.-M. Yeh, J. Wang, X. Jia, C. Yang and D. Jin, Polym. Mater. Sci. Eng., 74, 202 (1996).

38. Y. Wei, C. Yang, G. Wei and G. Feng, Synth. Met., 84, 289 (1997).

39. A. Takahara, J. Tashita, T. Kajiyana and M. Takayanage, Polymer, 26, 987 (1985).

40. Y. Z. Wang, K. H. Hsieh, L. W. Chen and H. C. Tseng, J. Appl. Polym. Sci., 49, 1047 (1993).

41. W. Yang, J. Shen and C. M. Chan, J. Appl. Sci., 67, 2035 (1998). 